\title{
In-Situ X-Ray Monitoring of Damage Accumulation in SiC/RBSN Tensile Specimens
}

George Y. Baaklini

Lewis Research Center

Cleveland, Ohio

and

Ramakrishna T. Bhatt

Propulsion Directorate

U.S. Army Aviation Systems Command

Lewis Research Center

Cleveland, Ohio

Prepared for the

15th Annual Conference on Composites and Advanced Ceramics sponsored by the American Ceramic Society Cocoa Beach, Florida, January 13-16, 1991 


\author{
George Y. Baaklini \\ National Aeronautics and Space Administration \\ Lewis Research Center \\ Cleveland, Ohio 44135 \\ and \\ Ramkrishna T. Bhatt \\ Propulsion Directorate \\ U.S. Army Aviation Research and Technology Activity-AVSCOM \\ Lewis Research Center \\ Cleveland, ohio 44135 \\ ABSTRACT
}

The room-temperature tensile testing of silicon carbide fiber-reinforced reaction-bonded silicon nitride (SiC/RBSN) composite specimens was monitored by using in-situ x-ray film radiography. Radiographic evaluation before, during, and after loading provided data on the effect of preexisting volume flaws (high density impurities and local density variations) on the fracture behavior of composites. Results from $[0]_{1},[0]_{3},[0]_{5}$, and [0] $]_{8}$ composite specimens, showed that $x-r a y$ film radiography can monitor damage accumulation during tensile loading. Matrix cracking, fiber-matrix debonding, and fiber pullout were imaged throughout the tensile loading history of the specimens. Further, in-situ film radiography was found to be a helpful and practical technique for estimating interfacial shear strength between the SiC fiber and the RBSN matrix by the matrix crack spacing method. It is concluded that pretest, in-situ, and post-test radiography can provide for a greater understanding of ceramic matrix composite mechanical behavior, a verification of related experimental procedures, and a validation and development of related analytical models.

\title{
INTRODUCTION
}

Ceramic matrix composite (CMC) systems are being developed for heat engine applications. ${ }^{1-3}$ The ultimate goal of current research is understanding of composite behavior in order to better optimize the composite properties for different hot section applications. CMC's are being developed because they provide enhanced 
material toughness while maintaining the useful properties of monolithic ceramics. The fiber-matrix interface in CMC's plays an important role in determining toughnessrelated properties, ${ }^{4,5}$ but there is very little quantitative data on interface properties. $^{4}$ Further, composite failure processes are not well understood because of a lack of reliable data.

In order to use CMC's more effectively, their failure processes and damage tolerances must be understood and, in turn, their failure analysis and mechanics models must be improved. Methodologies such as in-situ x-ray radiography and in-situ acoustic emission tests can help in imaging and sensing, respectively, the failure sequences and damage accumulation in composite specimens under loading. ${ }^{6,7}$ The information gathered from such in-situ monitoring can help in the development and validation of analytical models, and in coordinating between experiment and theory. Damage and failure mechanisms, e.g., transverse matrix cracking, fiber-matrix debonding, fiber breaking, fiber pullout, and delamination can be better understood if imaged and/or identified as they occur. Such in-situ examination will help identify and clarify the sequence in which these mechanisms take place, and consequently aid in identification of deformation controlling properties, i.e., whether they are matrix dominated properties, fiber dominated properties, or a combination of both.

The objectives of this study are to demonstrate the capabilities of in-situ $x$-ray radiography in monitoring damage accumulation and failure processes in unidirectionally reinforced $\mathrm{SiC/RBSN}$ system under tensile loading, and consequently, to determine the interfacial shear strength between the SiC fiber and the RBSN matrix. The major benefits of this research are: better interpretation of mechanical test results, validation of analytical models, verification of experimental procedures, and optimimization of the fabrication process. 


\section{EXPERIMENTAL}

In-situ $\mathrm{X}$-ray and Materials Testing system

An in-situ $x$-ray and materials testing system (IX-MTS) facility was built in order to conduct in-situ x-ray monitoring of materials under loading. Figure 1 shows a schematic diagram of the experimental set-up. Figures 2 and 3 show the IX-MTS and a close-up of the specimen testing/evaluation region. The IX-MTS consisted of an 3.2 kW x-ray system, and a electro-mechanical materials testing system.

The $\mathrm{x}$-ray system was capable of reaching $160 \mathrm{kV}$ or $45 \mathrm{~mA}$ with either a $400 \mu \mathrm{m}$ or a $3 \mathrm{~mm}$ focal spot size. Film radiography was the detection medium chosen because of its high resolution and registration capabilities. The materials testing system* consisted of a $250 \mathrm{kN}$ load frame, a $100 \mathrm{kN}$ electric-actuator, a $50 \mathrm{kN} 10 \mathrm{ad}$ cell, and a digital control system.

The room-temperature tensile testing was done in load control for some specimens and in displacement control for others. Loading and displacement rates were $4.54 \mathrm{~kg} / \mathrm{min}$ and $25 \mu \mathrm{m} / \mathrm{min}$, respectively. These relatively slow rates were used in order to perform in-situ film radiographic monitoring without holding the load or displacement. The load did not change by more than $10 \mathrm{~kg}$ during the radiographic exposure (25 to $35 \mathrm{sec}$ ) except at failure. As the tensile specimen was pulled, the axial strains were monitored by two adhesively bonded strain gauges and a clip-on extensometer. Two x-ray films were exposed at different stress-strain levels during the test.

The strain gauges were bonded to the faces of the specimen and the extensometer was clipped to the edge while leaving the $2.54 \mathrm{~cm}$ gauge length accessible to in-situ radiography. Immediately after the test, the specimen was evaluated with microfocus radiography and optical metallography. Films were then developed and radiographic images were made to interpret the results in conjunction with the stress-strain data.

\footnotetext{
*Instron Materials Testing System, Canton, Massachusetts.
} 


\section{Radiographic Evaluation}

Two different $\mathrm{x}$-ray systems were used: (1) a conventional system (conventionally designed $x$-ray tube) with a $400 \mu \mathrm{m}$ focal spot size and (2) a microfocus system with a $10 \mu \mathrm{m}$ focal spot size. Conventional radiographs were made in a direct contact mode (image is 100 percent of object) while microfocus radiographs were made in a projection mode with a resultant magnified radiographic image.

Conventional radiography was used to evaluate silicon powder cloths and composite panels before and after machining. Microfocus radiography was used to evaluate the tensile specimens before loading and after failure because of its high resolution capabilities. ${ }^{8}$

\section{Specimens}

The SiC/RBSN composite panels, $[0]_{1},[0]_{3},[0]_{5}$, and $[0]_{8}$, were produced by conventional ceramic powder fabrication methods ${ }^{9}$ using $142 \mu \mathrm{m}$ diameter sic fibers, designated as double coated scs-6 fibers. ${ }^{\star *}$ Reference 10 describes the method of preparing fiber-reinforced ceramic materials in details.

The radiographic evaluation of machined panels guided the choice of cutting tensile specimens with different density features from the composite panels:

(1) specimens with sizeable volumetric high density impurity located in the gauge length region, (2) specimens with many small high density impurities in the gauge length region, and (3) specimens with low density variations were chosen. Specimen dimensions were 125 by 12.7 by 1 to $2.0 \mathrm{~mm}$. The fiber volume fractions were 9 , 16 , 19, and 24 percent. Two axial wire-wound strain gauges were adhesively bonded to the front and back faces of each tensile specimen which had glass fiber-reinforced epoxy tabs.

\footnotetext{
${ }^{*}$ Textron Specialty Materials Division, Lowell, Massachusetts.
} 


\section{RESULTS}

Radiographic Characterization Prior To Testing

Figure 4 shows the radiographic image of a typical [0] 3 SiC/RBSN panel before and after machining the graphite layer. The graphite layer formed during the high temperature vacuum hot pressing composite fabrication. It is obvious from the radiographic print before machining that the graphite layer masks any density variation information from the SiC/RBSN panel, i.e., the density variation detected was mainly due to variation in the thickness and density of the graphite layer itself.

After machining the graphite layer, radiographic characterization of the composite panels was possible. The fiber architecture was detected, for example, the orientation of the fibers as evident in Fig. 4, and fiber bunching and misalignment in other panels (not shown) were detected. High density impurities, i.e., the dark isolated features (black dots) which are shown in Fig. 4(b), were chemically identified as iron rich inclusions. Figure $4(b)$ also shows localized low density (light to white) due to surface chipping.

\section{Mechanical Properties}

The room temperature tensile stress-strain behavior for the $[0]_{1},[0]_{3},[0]_{5}$, and $[0]_{8} \mathrm{SiC} / \mathrm{RBSN}$ are shown in Fig. 5, and corresponding tensile property data are listed in Table I. The values of the rule of mixtures composite modulus, ${ }^{11} E_{(\text {rom)c }}$. which is given by

$$
E_{(\text {Iom }) c}=E_{m} V_{m}+E_{f} V_{f}
$$

where $\mathrm{E}$ is modulus, $\mathrm{V}$ is volume fraction, and $\mathrm{C}, \mathrm{f}$, and $\mathrm{m}$ refer to composite, fiber, and matrix, are given in Table $I$. The $E_{m}$ and $E_{f}$ values used were $390 \mathrm{MPa}$ and $110 \mathrm{MPa}$ respectively. ${ }^{9}$

The stress-strain results for the $[0]_{1}$ and the $[0]_{3}$ showed a linear behavior until final fracture. At the ultimate stress the specimens which were tested in the 
load control mode failed catastrophically. Specimens tested in the displacement control mode showed load dropping region before final failure. Radiography showed that in this region fiber pullout was the dominant failure mechanism.

The stress-strain results for the $[0]_{5}$ specimens showed three distinct regions. In the initial region the stress varied linearly with the strain up to an average stress level of $197 \mathrm{MPa}$ when the load momentarily dropped. In the second region the stress strain curve became nonlinear and displayed serrations due to load dropping and recovering without exceeding an average engineering stress of $226 \mathrm{MPa}$. The third region showed a fiber pullout behavior where load was dropping but not as catastrophically as at the final failure.

The stress-strain results for the $[0]_{8}$ specimen showed three distinct regions. In the initial region, the stress varied linearly with the strain up to a stress level of approximately $195 \mathrm{MPa}$ when matrix cracking was evident. In the second region the behavior was nonlinear where load was either holding or dropping then recovering and increasing as the strain was increasing. In the third region, the stress varied linearly with the strain in segments where modulus was either the same or decreasing until maximum tensile stress was reached, thereafter the specimen showed minor load carrying capacity before it finally fractured.

\section{In-situ Radiographic Imaging}

Figure 6 shows microfocus radiographs of $[0]_{1}$ specimen. These radiographs were taken before loading the specimen and after it failed. The before-loading image shows a subsurface 0.5 by $1.0 \mathrm{~mm}$ high density impurity. This high density region consisted of a cluster of $50 \mu \mathrm{m}$ diameter inclusions. The after-failure image shows that the fracture initiated at the site of the impurity and propagated across the width of the sample. This was inferred from the size and number of the fiber pullouts seen. A closer look at the radiographic film showed the presence of multiple breakages per fiber. Figure $6(\mathrm{c})$ shows that microfocus radiography detects $40 \mu \mathrm{m}$ fiber pullout. 
Figure $7(a)$ and (b) show microfocus radiographs of two different [0] $]_{1}$ specimens after failure. These radiographs show random fibers pullout and multiple matrix cracks. These cracks did not propagate through the thickness of the specimens because of fiber-matrix debonding at the fiber-matrix interface. Similarly, in Fig. $7(\mathrm{c}),[0]_{3}$, through-width but not through-thickness cracks, fibers pullout, and fiber-matrix debonding are present. The white region near the right of Fig. $7(\mathrm{C})$ is an indication of extensive fiber-matrix debonds which has also occurred outside the $2.54 \mathrm{~cm}$ gauge length (the area between the two bonded strain gauges).

Figure 8 shows three radiographs R6, R8, and R10 selected out of a series of 10 in-situ radiographs taken throughout the tensile loading history of a $[0]_{5}$ specimen. The stress-strain behavior is also shown. In Fig. 8, although radiographs were made at R3, R4, and R5 they did not show the presence of matrix cracking. R6 shows one major through-width crack. R8 shows multiple cracks. R10, taken after failure shows the resulting fibers pullout, the closure of the cracks imaged earlier, and the major cracks with corresponding fiber-matrix debonds region at failure. Radiographs for R7 and R9 show similar information but they were not included because of space limitations in Fig. 8.

Figure 9 shows selected in-situ radiographs made during tensile loading history of a $[0]_{8}$ specimen. RO is a radiographic print of the specimen at near $0 \mathrm{~kg} l o a d$. R8 is a radiographic print of the specimen at $268 \mathrm{MPa}$ and 0.2 percent strain. This radiograph, R8, shows 6 cracks perpendicular to the fiber orientation, propagating from right to left but not all the way through the width of the specimen. Figure 10 and Table II present a detailed summary of the crack development and corresponding spacing data imaged in R8. Radiographs $\mathrm{R} 9$ and R10 in Fig. 9 show 10 throughthickness and through-width matrix cracks at 410 and $538 \mathrm{MPa}$, respectively. 
Figure 11 is a schematic of the matrix crack spacing method for calculation of estimated interfacial shear strength, $\tau_{f}$ based on the Aveston, Cooper, and Kelly (ACK) theory ${ }^{12}$

$$
\tau_{f}=\frac{\sigma_{c}^{m} D_{f}}{2.98(\bar{X}) V_{f}\left(1+E_{f} V_{f} / E_{m} V_{m}\right)}
$$

where $\boldsymbol{\sigma}_{c}^{m}$ is the composite stress corresponding to the first matrix crack, $\bar{x}$ is the mean crack spacing, $D_{f}$ is the fiber diameter, and the rest of the terms are as defined earlier in Eq. (1). For [0] $]_{8}$ with, 24 percent fiber volume fraction, $3.56 \mathrm{~mm}$ mean crack spacing, $195 \mathrm{MPa}$ composite stress at first matrix crack, $390 \mathrm{MPa}$ fiber modulus, and $110 \mathrm{MPa}$ matrix modulus the interfacial shear strength was calculated from Eq. (2) to be $5 \mathrm{MPa}$.

\section{DISCUSSION}

\section{Significance of Radiographic Characterization}

The radiographic results of silicon powder cloths and SiC/RBSN panels helped identify: (1) the presence and type of impurities, and (2), the local density variations within each panel and between panels. This information presented options in designing the tensile specimens from the panels. Specimens that contained large volumetric flaws can be monitored and compared with specimens that were free of these flaws. Specimens that contained excessive local density variations can be compared with specimens that had minor local density variations. Consequently, based on whether or not impurities and local density variations are affecting the fracture behavior of the composite, materials engineers can modify powder processing or composite fabrication in order to free the composite from detrimental defects. In this study, it was found that a $0.5 \mathrm{~mm}$ by $1.0 \mathrm{~mm}$ high density region can affect the fracture behavior of the $[0]_{1}$ composite (Fig. 6) because the latter is behaving more like monolithic with one linear region ending in a catastrophic failure at ultimate stress (Fig. 5). However, isolated and randomly distributed high density inclusions less than $150 \mu \mathrm{m}$ in diameter did not directly affect the fracture behavior 
of the $[0]_{1}$ and $[0]_{3}$ composite specimens. Similarly high density inclusions up to $225 \mu \mathrm{m}$ in diameter did not affect the fracture behavior of the $[0]_{5}$ composite specimens. Local density variations within the tensile specimens did not seem to affect the fracture behavior of the composite. These are preliminary conclusions based on the limited number of samples that have been monitored and tested.

Microfocus radiography of failed specimens proved useful in detecting fibers pullout. Cracks and crack branchings that had not closed after failure were imaged. This shows advantages of microfocus over conventional radiography in studying and explaining the behavior of composites under load.

\section{Mechanical Properties}

The primary modulus, before first matrix cracking of the composite, $E_{p c}$ was about the same, within 12 percent, for all $[0]_{1},[0]_{3},[0]_{5}$ and $[0]_{8}$ composite specimens. These primary moduli either overestimated by 12 percent or came close to 1 percent of the corresponding rule of mixtures composite modulus, $E_{(\text {rom }) c^{\prime}}$ defined in Eq. (1). This overestimate can be explained by the fact that one-ply, three-ply, and five-ply materials were thinner and hence denser than the normal RBSN matrix where a modulus of $110 \mathrm{MPa}$ is expected. The fact that, $\mathrm{E}_{\mathrm{pc}}$ 's are close to $\mathrm{E}_{\text {(rom)c }}$ 's, is indicative of an adequate load transfer between fibers and matrix. ${ }^{13}$

The first matrix cracking strains and stresses of $[0]_{1}$, and $[0]_{3}$ were also the strain-to-failure values and the ultimate strengths of these specimens, respectively. In contrast, first matrix stress and strain for [0] (19 percent volume fraction) were very close to those of $[0]_{8}$ ( 24 percent volume fraction), where the strain to failure showed great enhancement over the one-ply, the three-ply, and the 5-ply composite specimens.

The ultimate tensile strength increased with the fiber volume fraction of all composite specimens because it is primarily controlled by the bundle strength of the fibers. ${ }^{13}$ 
Significance of In-situ Radiography

In the case of $[0]_{1}$ and $[0]_{3}$ composites, in-situ radiography was able to immediately image cracks and fiber pullout after failure occurred at ultimate strength. This was only achieved when the samples were tested in displacement control. Under load control catastrophic failure occurring at ultimate strength prevents the operator from making an $x$-ray exposure. In-situ radiography during failure and in-situ and microfocus radiography immediately after failure helped identify the presence and location of non transparent matrix cracks on the ply level, of nontransparent fiber pullout, and of fiber matrix debonding.

In the case of $[0]_{5}$, failure sequences were radiographically imaged in the nonlinear region, and during and after the fiber pullout region (Fig. 8). Breakages of fibers can not be imaged until fibers start pulling apart. Microcracks which may have existed in the linear region, can not be imaged because of limitations in the resolution and the detection capabilities of the $\mathrm{x}$-ray system. The first matrix crack was imaged after the stress-strain curve had indicated that matrix cracking occurred. Thereafter, multiple cracks were imaged as the specimen was strained, then fibers started to pull out and the matrix cracks started to close until the final failure of the composite. At this point major fiber pullout, fiber matrix debonding and fiber breakage were imaged. After failure, close optical examination demonstrated that matrix cracks had propagated across the width of the sample but not through the thickness.

In the case of $[0]_{8}$, in-situ radiography imaged matrix crack develop throughout the tensile loading history as shown in Figs. 9 and 10 and as summarized in Table II. In-situ radiography enabled the use of the mean crack spacing method to determine the interfacial shear strength as defined in Eq. (2), and also verified the usual experimental procedure ${ }^{14}$ used to determine $\tau_{f}$. From Table II and Fig. 9, it is apparent that the number of major matrix cracks and corresponding spacings have not changed between 71 and 93 percent of ultimate engineering strength. This 
verifies that the procedure to unload the sample at about 75 percent ${ }^{14}$ of ultimate load to perform the crack spacing measurements under an optical microscope was done in the proper loading region. This $x-r a y$ monitoring technique is ideal when compared with its optical counterpart, ${ }^{14}$ because, first stopping the test and unloading is not practical. Second, estimating the presence of cracks which have already closed due to unloading leads to an overestimate of $\tau_{f}$. Third, the ultimate strength is real not estimated from other similar samples. And fourth, if the sample shatters into fragments after failure or fails earlier than expected the cracks have already been imaged and spacings can be measured from the x-ray film. Further, even in-situ optical monitoring will not deliver the above information; because the high magnification needed to monitor the cracks reduces the imaging field and the working focal length.

\section{CONCLUSION}

In-situ radiography of room temperature tensile testing of sCs-6 silicon carbide fiber reinforced reaction-bonded silicon nitride (SiC/RBSN) composite specimens is a good method for monitoring damage accumulation, and for determining the interfacial shear strength between the SiC fiber and the RBSN matrix by the matrix crack spacing method. Matrix cracking, fiber-matrix debonding, and fiber pullout were imaged throughout the loading history of the specimens. Radiographic evaluation before, after, and during loading provided data on the effect of preexisting volume flaws, e.g., high density inclusions, and on the effect of local density variations on the fracture behavior of composites. It is concluded that this approach can provide a basis for interpretation of mechanical tests, for validation of analytical models, and for verification of experimental procedures.

\section{REFERENCES}

${ }^{1}$ T. Mah, M.G. Mendiratta, A.P. Katz, and K.S. Mazdiyasni, "Recent Developments in Fiber-Reinforced High-Temperature Ceramic Composites," Am. Ceram. Soc. Bull., 66 [2] 304-308 (1987). 
${ }^{2}$ L. Heraud, P. Spriel, High Toughness C-SiC and SiC-SiC Composites in Heat Engines. Whisker- and Fiber-toughened Ceramics. R.A. Bradely, et al., eds., ASM International, pp. 217-224, 1988.

${ }^{3}$ R.T. Bhatt, The Properties of Silicon Carbide Fiber-Reinforced silicon Nitride Composites. Whisker- and Fiber-Toughened Ceramics. R.A. Bradely, et al., eds, ASM International, pp. 199-208, 1988.

${ }^{4}$ R.J. Kerans, R.S. Hay, N.J. Pagano, and T.A. Parthasarathy, "The Role of the FiberMatrix Interface in Ceramic Composites," Am. Ceram. Soc. Bull., 68, pp. 429-442, 1989 .

${ }^{5}$ A.G. Evans and D.B. Marshall, "The Mechanical Behavior of Ceramic Matrix Composites," Overview No. 85, Acta metall. 37, [10], pp. 2567-2583, 1989.

${ }^{6}$ G.Y. Baaklini, and R.T. Bhatt, "Preliminary x-ray monitoring of Damage Accumulation in SiC/RBSN," HITEMP Review-1990, NASA CP-10051, pp. 54-1 to 54-13.

7A. Chulya, G.Y. Baaklini, and R.T. Bhatt," Characterization of Damage and Fracture Mechanisms in Continuous Fiber-Reinforced SiC/RBSN Ceramic Matrix Composites," HITEMP Review-1990, NASA CP-10051, pp. 55-1 to 55-15.

${ }^{8}$ G.Y. Baaklini, and D.J. Roth, "Probability of Detection of Internal Voids in Structural Ceramics using Microfocus Radiography," J. Mater. Res., 1, [3], pp 457-467 May-June 1986.

${ }^{9}$ R.T. Bhatt, and R.E. Phillips, "Laminate Behavior for SiC Fiber-Reinforced Reaction-Bonded Silicon Nitride Matrix Composites," NASA TM-101350, 1988.

${ }^{10}$ R.T. Bhatt, "Method of Preparing Fiber-Reinforced Ceramic Materials," U.S. Pat. No. $4689188,1987$.

${ }^{11}$ B.D. Agarwal and L.J. Broutman, in Analysis and Performance of Fiber Composites, Chapter II, John Wiley \& Sons, New York 1979.

${ }^{12} \mathrm{~J}$. Aveston, G.A. Cooper, and A. Kelly, "Single and Multiple Fracture," in The Properties of Fiber Composites, Proceedings of the conference, pp. 15-26, IPC Science and Technology Press ltd., Surrey, England, 1971. 
${ }^{13}$ R.T. Bhatt, "Influence of Interfacial Shear Strength on the Mechanical Properties of SiC Fiber Reinforced Reaction-Bonded Silicon Nitride Matrix Composites," NASA TM-102462, 1990 .

${ }^{14}$ R.T. Bhatt, "Mechanical Properties of SiC Fiber-Reinforced Reaction-Bonded Si ${ }_{3}{ }_{4}$ Composites," NASA TM-87085, 1985.

Table I.-Room temperature tensile property data for SiC/RBSN composite specimens.

\begin{tabular}{|c|c|c|c|c|c|c|c|}
\hline \multirow[t]{2}{*}{ SiC/RBSN } & \multirow{2}{*}{$\begin{array}{l}V_{f}, \\
\%\end{array}$} & \multirow{2}{*}{$\begin{array}{l}\text { Number } \\
\text { of } \\
\text { specimens }\end{array}$} & \multirow{2}{*}{$\begin{array}{c}\mathrm{E}_{\mathrm{C}} \text {, } \\
\mathrm{GPa} \\
\text { experimental }\end{array}$} & \multirow{2}{*}{$\begin{array}{c}\mathrm{E}_{\mathrm{C}}{ }^{*}, \\
\mathrm{GPa} \\
\text { rule of } \\
\text { mixtures }\end{array}$} & \multirow{2}{*}{$\begin{array}{c}\sigma, \\
\mathrm{MPa} \\
\text { ultimate }\end{array}$} & \multicolumn{2}{|c|}{ Proportional limit } \\
\hline & & & & & & $\begin{array}{c}\sigma \\
\mathrm{MPa}\end{array}$ & $\begin{array}{l}\varepsilon, \\
\%\end{array}$ \\
\hline$[0]_{1}$ & 9 & 5 & 160 & 135 & 129 & 129 & 0.08 \\
\hline$[0]_{3}$ & 16 & 1 & 178 & 155 & 178 & 178 & 0.10 \\
\hline$[0]_{5}$ & 19 & 3 & 180 & 163 & 226 & 197 & 0.11 \\
\hline$[0]_{8}$ & 24 & 1 & 175 & 177 & 576 & 195 & 0.12 \\
\hline
\end{tabular}

* $E_{c}=E_{m} V_{m}+E_{f} V_{f}$ where $E_{m}=110 \mathrm{GPa} \& E_{f}=390 \mathrm{GPa}$ (ref. 9).

Table II.-Variation of crack density versus load for SiC-RBSN Composite ( $V_{f} \approx 24 \%$ )

\begin{tabular}{|c|c|c|c|c|c|}
\hline $\begin{array}{c}\text { Radiograph } \\
\text { number }\end{array}$ & $\begin{array}{c}\text { Stress, } \\
\mathrm{MPa}\end{array}$ & $\begin{array}{c}\text { Strain, } \\
\%\end{array}$ & $\begin{array}{c}\% \text { of } \\
\text { ultimate } \\
\text { (ult =576 MPa) }\end{array}$ & $\begin{array}{c}\text { Number of } \\
\text { cracks } \\
\text { detected by } \\
\text { x-rays }\end{array}$ & $\begin{array}{c}\text { Mean crack } \\
\text { spacing, } x \\
\mathrm{~mm}\end{array}$ \\
\hline R4 & 219 & .14 & 38 & $1^{*}$ & - \\
\hline R5 & 226 & .15 & 39 & $2^{*}$ & - \\
\hline R6 & - & - & - & $3^{*}$ & 8.56 \\
\hline R7 & 258 & .18 & 45 & $5^{*}$ & 8.02 \\
\hline R8 & 268 & .20 & 47 & $6^{*}$ & 6.42 \\
\hline R9 & 410 & .40 & 71 & $10^{* *}$ & 3.56 \\
\hline R10 & 538 & .55 & 93 & $10^{* *}$ & 3.56 \\
\hline R12 & & After failure & $11^{* *}$ & 3.47 \\
\hline
\end{tabular}

- Not across - width cracks.

** Across-width and through-thickness cracks. 


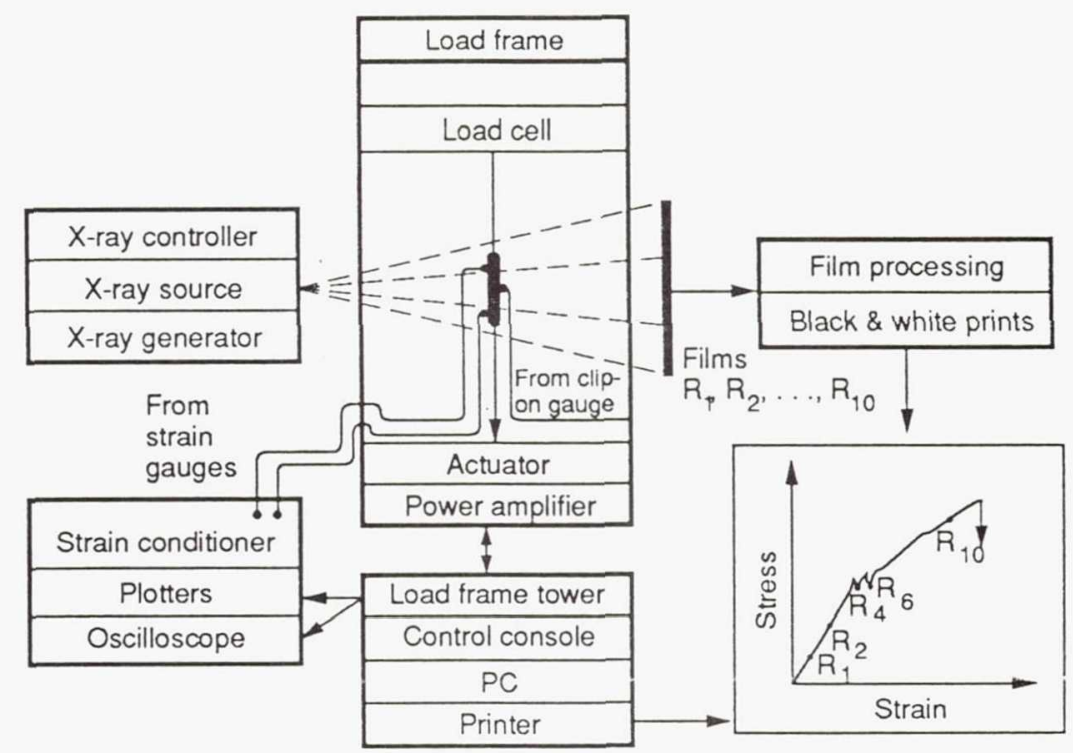

Figure 1.-Schematic diagram of the In-situ $x$-ray and materials testing system.

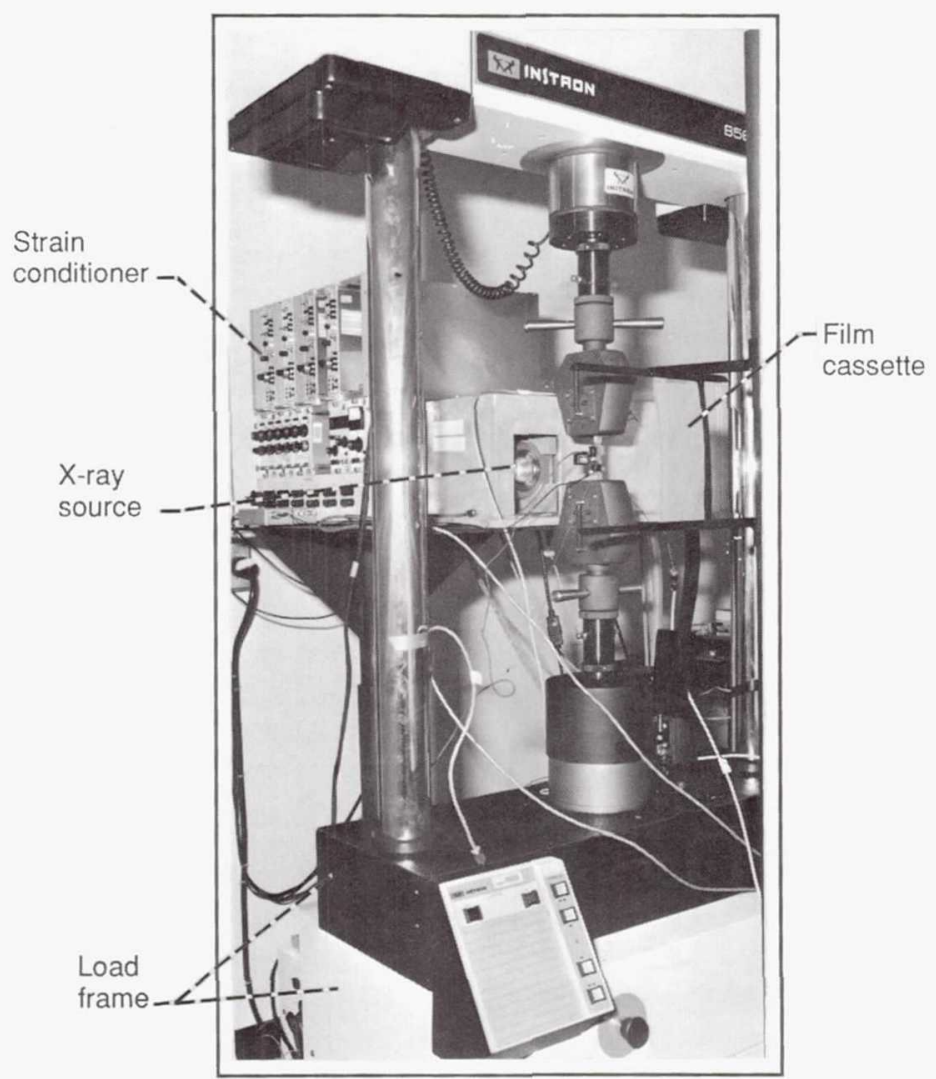

Figure 2.- In-Situ x-ray and materials testing system. 


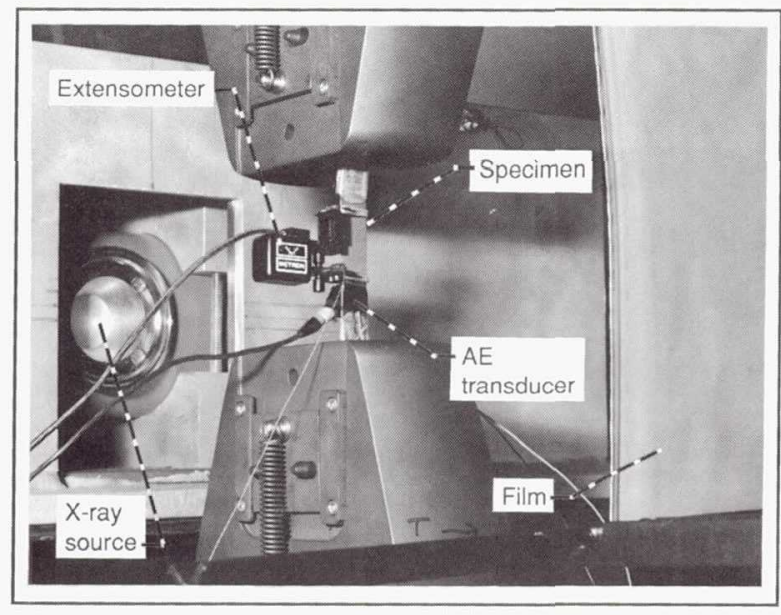

Figure 3.-Detail of In-situ x-ray materials testing system.

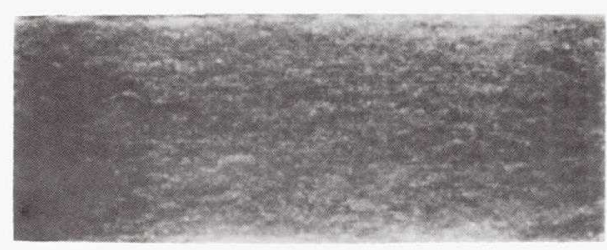

(a) Before

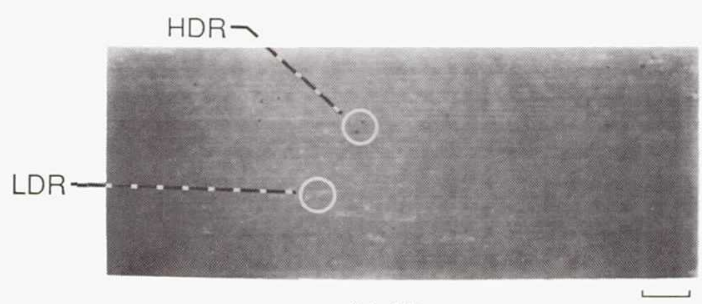

(b) After.

$1 \mathrm{~cm}$

HDR - High-density region

LDR - Low-density region

Figure 4.-Conventional radiographs of $[0]_{3}$ panel before and after maching.

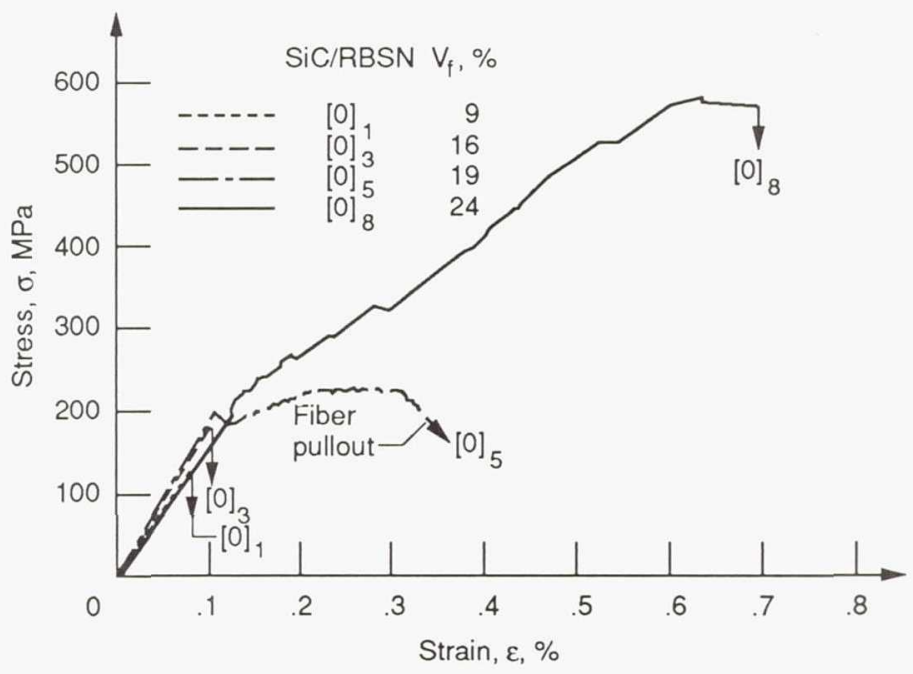

Figure 5. Room temperature stress-strain behavior for unidirectionally reinforced SiC/RBSN composite specimens. 


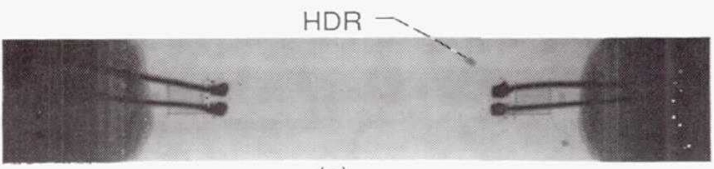

(a)

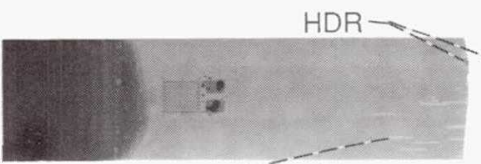

$F P-(b)$

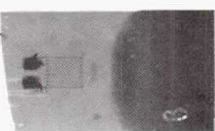

HDR $\rightarrow$

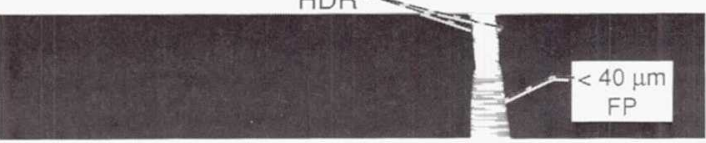

(c)

- FP - fiber pullout

- HDR - high-density region

Figure 6.-Microfocus radiographs of a [0] SiC/RBSN specimen.
Before

loading

After

failure

After

failure

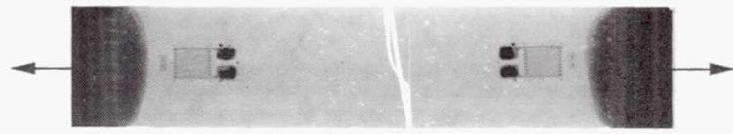

(a) $[0]_{1}$

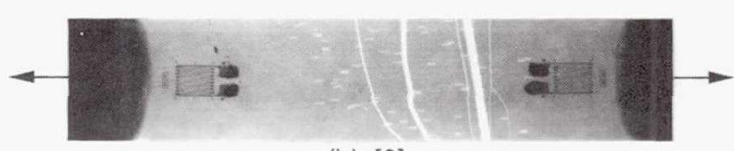

(b) $[0]_{1}$

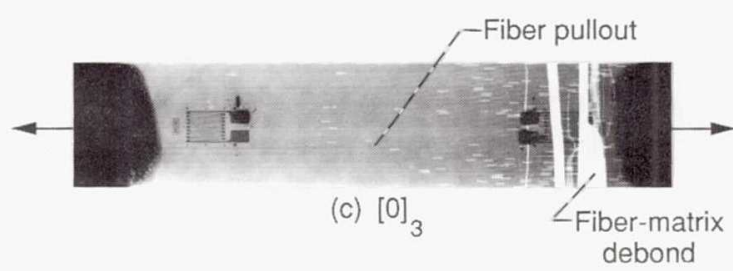

Figure 7.-Microfocus radiographs of SiC/RBSN specimens after failure.

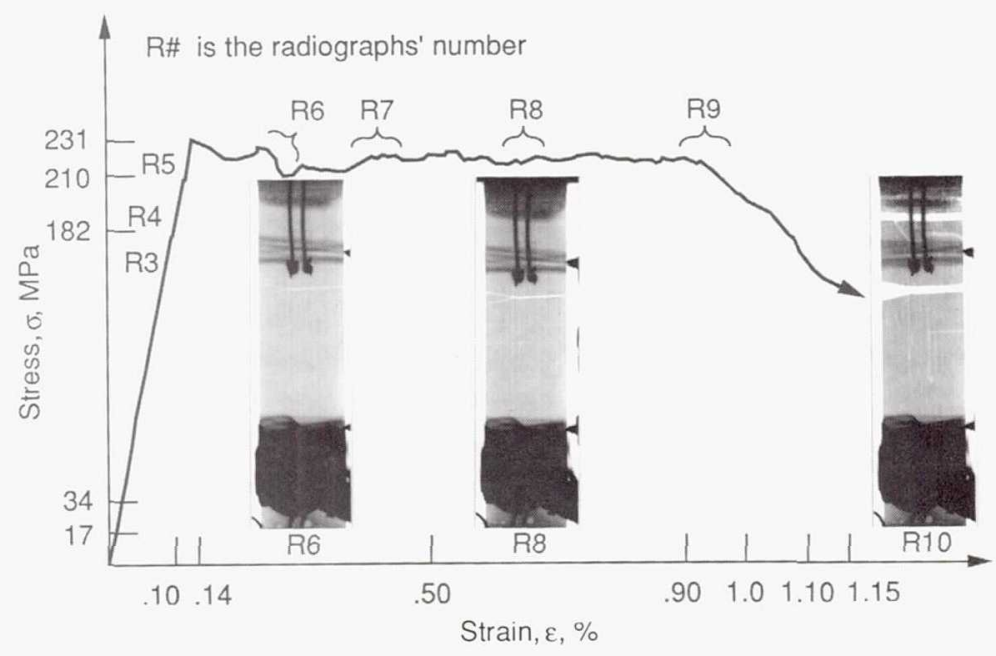

Figure 8.-Selected In-situ radiographs obtained during tensile loading of a $[0]_{5}$ SiC/RBSN composite $\left(V_{f} \approx 19 \%\right)$. 


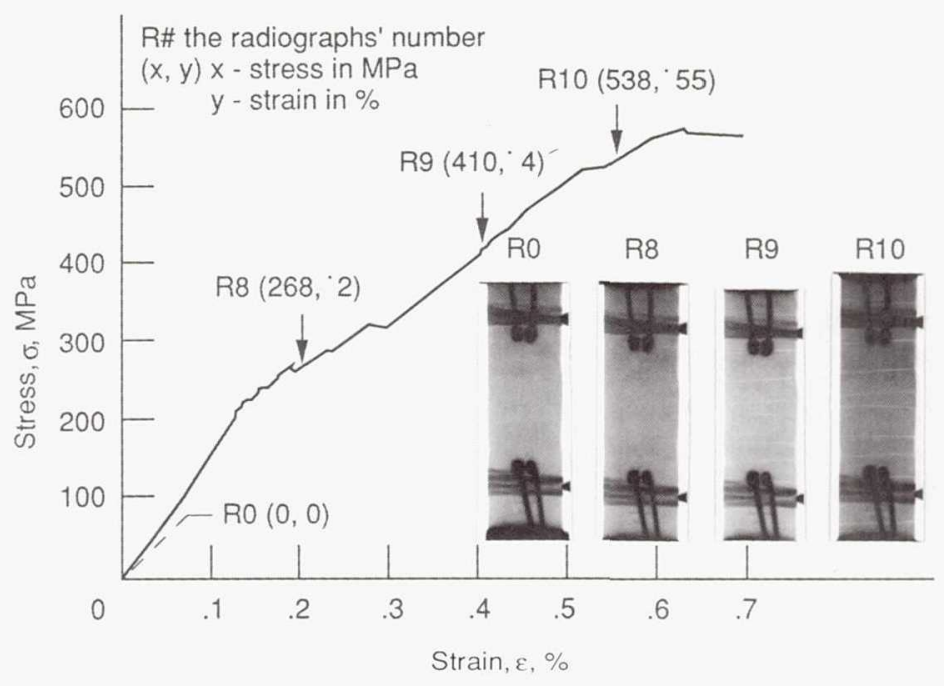

Figure 9.-Selected In-situ radiographs obtained during tensile loading of a $[0]_{8}$ SiC/RBSN composite $\left(V_{f} \approx 24 \%\right)$.

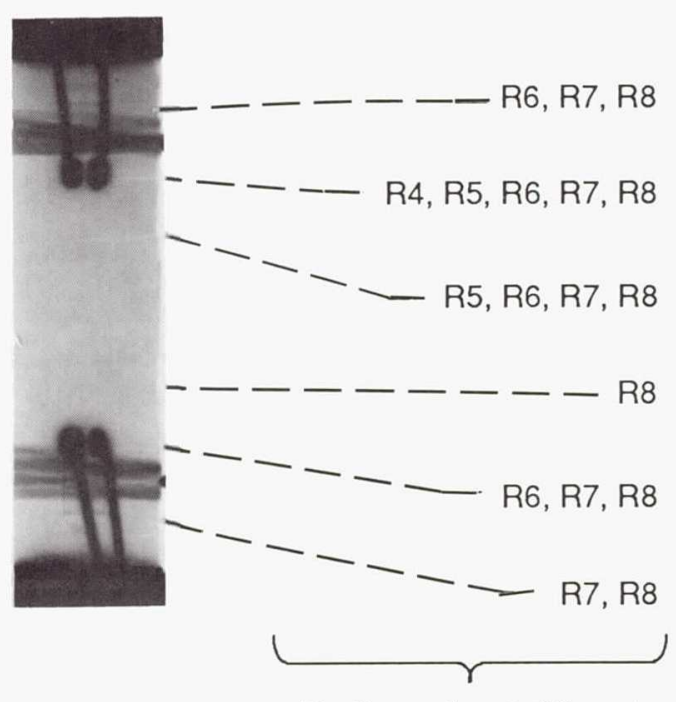

Radiographs at different stages of loading.

Figure 10.-Summary of resulting crack density as presented on radiograph number R8 at 268 $\mathrm{MPa}$ and $0.2 \%$ strain.
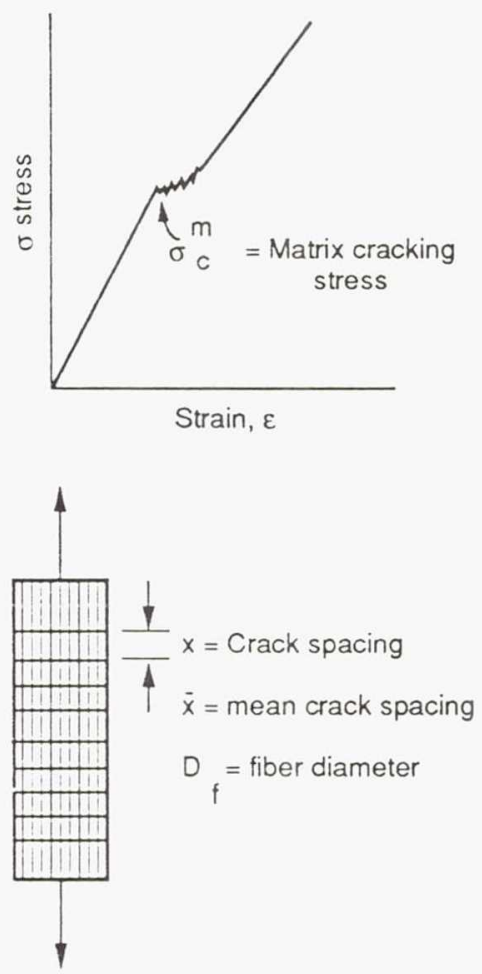

$$
\tau_{f}^{*}=\frac{\sigma_{c}^{m} D_{f}}{2.98(\bar{x}) V_{f}\left(1+E_{f} V_{f} / E_{m} V_{m}\right)}
$$

- Aveston, Cooper, and Kelly

Figure 11. - Matrix crack spacing method $\left(\tau_{f}\right)$. 


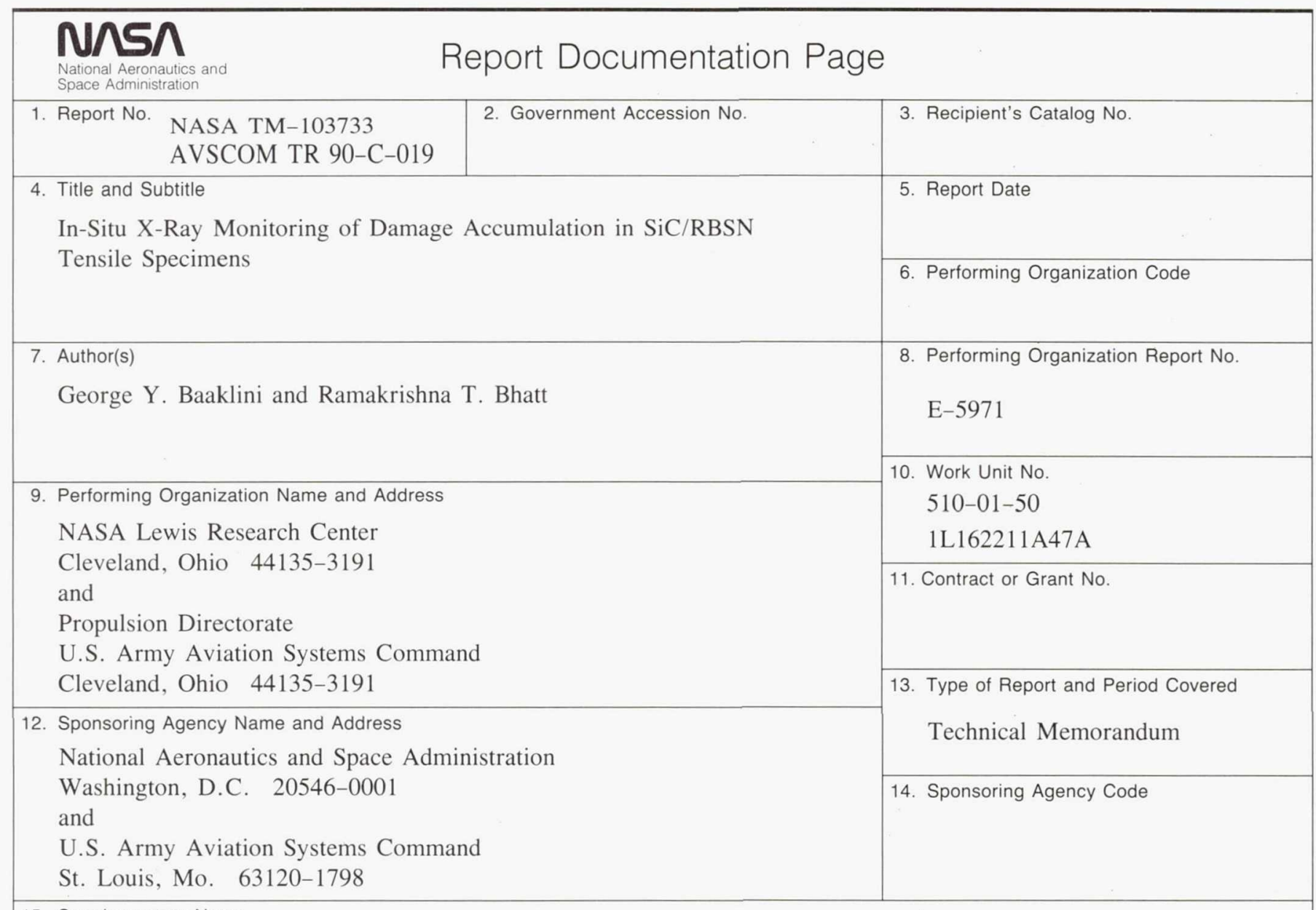

15. Supplementary Notes

Prepared for the 15th Annual Conference on Composites and Advanced Ceramics, sponsored by the American Ceramic Society, Cocoa Beach, Florida, January 13-16, 1991. George Y. Baaklini, NASA Lewis Research Center; Ramakrishna T. Bhatt, Propulsion Directorate, U.S. Army Aviation Systems Command. Responsible person, George Y. Baaklini, (216) 433-6016.

16. Abstract

The room-temperature tensile testing of silicon carbide fiber-reinforced reaction-bonded silicon nitride (SiC/RBSN) composite specimens was monitored by using in-situ $\mathrm{x}$-ray film radiography. Radiographic evaluation before, during, and after loading provided data on the effect of preexisting volume flaws (high density impurities, and local density variations) on the fracture behavior of composites. Results from $[0]_{1},[0]_{3},[0]_{5}$, and $[0]_{8}$ composite specimens, showed that x-ray film radiography can monitor damage accumulation during tensile loading. Matrix cracking, fiber-matrix debonding, and fiber pullout were imaged throughout the tensile loading history of the specimens. Further, in-situ film radiography was found to be a helpful and practical technique for estimating interfacial shear strength between the $\mathrm{SiC}$ fiber and the RBSN matrix by the matrix crack spacing method. It is concluded that pretest, in-situ, and post-test radiography can provide for a greater understanding of ceramic matrix composite mechanical behavior, a verification of related experimental procedures, and a validation and development of related analytical models.

17. Key Words (Suggested by Author(s))

$\mathrm{X}$-Ray monitoring; Damage accumulation; Ceramic composites; HITEMP materials; NDE; Mechanical test; Failure processes; $\mathrm{SiC} ; \mathrm{Si}_{3} \mathrm{~N}_{4} ; \mathrm{SiC} / \mathrm{RBSN}$
18. Distribution Statement

Unclassified - Unlimited

Subject Categories 24, 38 and 39
19. Security Classif. (of this report)

Unclassified
20. Security Classif. (of this page)

Unclassified
21. No, of pages

18
22. Price* $\mathrm{A} 03$ 